\title{
Supporting 'expert' parents - professional support and families caring for a child with complex health care needs in the community
}

\author{
Susan Kirk*, Caroline Glendinning \\ National Primary Care Research and Development Centre, University of Manchester, The Williamson Building, \\ Oxford Road, Manchester M13 9PL, UK
}

Received 19 July 2001; accepted 29 November 2001

\begin{abstract}
In the United Kingdom a new group of children with intensive and complex health care needs are now being cared for at home as a result of medical advances and government policies emphasising the community as the arena for care. This has led their parents to become involved in providing care of a highly technical and intensive nature that would previously have been considered to be the domain of professionals. In-depth qualitative interviews were conducted with parents and professionals to discover parents' and professionals' experiences of receiving and providing support in a context where parents rather than professionals are the expert caregivers. This paper describes the elements of professional 'support' that were particularly valued by parents and concludes with a discussion of the implications for professional education and roles. (C) 2002 Elsevier Science Ltd. All rights reserved.
\end{abstract}

Keywords: Technology-dependent children; Nursing; Professional support

\section{Introduction}

Advances in medicine have led to increased survival rates for pre-term infants and those born with congenital impairments and improved the prognosis for children with chronic diseases and cancer. These advances, combined with a policy emphasis in the United Kingdom (UK) on caring for disabled and sick children in their own homes (Department of Health, 1991, 1996), mean that a small but growing (Glendinning et al., 2001) group of children with complex and continuing health care needs are now being cared for at home. Some of these children depend on complex medical technologies such as mechanical ventilation, renal dialysis or intravenous drug therapies, for their survival. These "technology-dependent" children are a sub-set of both the chronically ill and disabled child populations, but

\footnotetext{
*Corresponding author. Tel.: +44-161-275-7601; fax: +44161-275-7600.

E-mail address: sue.kirk@man.ac.uk (S. Kirk).
}

distinguished by both the level and the nature of the care they require.

The research reported in this paper involved a sample of families with a technology-dependent child. The parents were responsible for the day-to-day management of their child's condition and performed highly technical clinical procedures which in hospital would be considered the domain of professionals-for example, changing tracheostomy tubes or administering intravenous medications. The performance of such activities, on which the child's life often depended, moves and blurs the boundaries between lay and professional roles. This paper examines the roles which professionals, particularly nurses, consequently play in supporting parents who are providing this highly skilled, "handson" nursing care for their children. The subject is examined from two perspectives, that of the parents and that of professionals.

Previous research has demonstrated the considerable social, emotional and financial costs of caring for children who are disabled, chronically ill or 
technology-dependent (Glendinning, 1983; Eiser, 1993; Baldwin and Carlisle, 1994; Beresford, 1995; Kirk, 1998). Common experiences include social isolation, exhaustion, stress, financial and marital problems. However, families with a technology-dependent child experience additional problems arising from the impact of the child's medical equipment on the home environment, a loss of privacy and the particularly complex and specialised nature of their caring role.

Previous research has also shown that parents need information, emotional support, practical assistance, financial help and a break from caring. Parents value continuity of relationships with professionals, especially if one can adopt a key worker role (Glendinning, 1983; Sloper and Turner, 1992; Whyte, 1992; Baldwin and Carlisle, 1994; Stewart et al., 1994; Gravelle, 1997). However, a consistent theme in previous studies has been the problems that families encounter in receiving support from services (Middleton, 1998). Delays are reported in the provision of services and parents have to fight to receive support (Glendinning, 1985; Young et al., 1988; Jennings, 1990; Diehl et al., 1991; Beresford, 1994, 1995; Petr et al., 1995; Chamba et al., 1999). Services are reported to be fragmented and poorly co-ordinated (Young et al., 1988; Diehl et al., 1991; Wheeler and Lewis, 1993; Hall, 1996), with only a minority of families having a key worker who can provide a first point of contact and co-ordinate a complex range of services (Sloper and Turner, 1992; Beresford, 1995; Hall, 1996; Chamba et al., 1999; Department of Health, 1998; Kirk, 1999). Parent's dissatisfaction with information-giving is frequently reported (Hayes and Knox, 1984; Andrews and Nielson, 1988; Jennings, 1990; Diehl et al., 1991; Sloper and Turner, 1992; Stallard and Lenton, 1992; Beresford, 1994, 1995; Stewart et al., 1994; Hall, 1996; Coyne, 1997; Chamba et al., 1999). Difficulties in obtaining medical equipment in the home appears to be a particular problem for the parents of technologydependent children (Andrews and Nielson, 1988; Aday et al., 1989; Quint et al., 1990; Kirk, 1999). Studies have repeatedly reported difficulties in obtaining a break from caring (Diehl et al., 1991; Wheeler and Lewis, 1993; Youngblut et al., 1994; Beresford, 1995; Petr et al., 1995; Hall, 1996; Chamba et al., 1999; Kirk, 1999); again, the parents of technology-dependent children appear to face particular problems in obtaining short-term care appropriate for their children's needs. Moreover, it is not just parents who are reported to have unmet needs but also the children themselves and their siblings (Baldwin and Carlisle, 1994).

Relationships with professionals rather than be supportive may themselves constitute an additional source of stress (Young et al., 1988; Aday et al., 1989; Scharer and Dixon, 1989; Diehl et al., 1991; McKeever, 1991; Pelletier et al., 1993; Beresford, 1994, 1995; Stewart et al., 1994; Hall, 1996; Coyne, 1997; Kirk,
2001). Problems identified by parents in their relationships with professionals include a lack of emotional support, a lack of empathy and an apparent failure to acknowledge parents' experiential knowledge. The quality of parent-professional relationships appears particularly important, as even parents who have high levels of contact with professionals can report extensive unmet needs and dissatisfaction with services (Sloper and Turner, 1992). This latter, counter-intuitive finding prompts more detailed investigation into the activities of professionals and the perceptions of both professionals and parents about their respective roles and relationships, both desired and actual. Moreover, in view of the unquestionably heavy and highly stressful responsibilities carried by parents with technology-dependent children, it is important that the help given by professionals should be as effective as possible. This means ensuring that professional interventions are informed by a sensitive understanding of parents' roles, their feelings about these roles and their perceptions of the needs that stem from these roles.

In this paper we will argue that the level, complexity and intensity of the nursing care which parents of technology-dependent children are required to provide is distinctive and sets them apart from their peers whose children do not require intensive, highly specialised technical nursing care. This key fact blurs the conventional distinctions between professionals whose status is based on ownership of a distinct and exclusive body of 'expert' knowledge and non-expert 'lay' people (Stacey, 1994) and calls into question the appropriateness of relationships which assume and are based upon this clear division. Instead, the paper will show how the nature of the care which parents provide for their technology-dependent children has a profound impact on their expectations and experiences of their relationships with professionals - an impact which is not always fully acknowledged by the professionals concerned.

As much of the additional care which parents provide for a technology-dependent child would, in a hospital setting, be the responsibility of nursing staff, the restructuring of relationships between parents and nursing professionals is of particular interest. How do nurses perceive, and respond to, the needs of parents, in this unusual context? Conversely, how do parents articulate their needs for professional support and to what extent and under what conditions are these needs met? What barriers to the provision of effective support appear to exist and how might these be overcome?

Within the UK, parents caring at home for a technology-dependent child may come into contact with a number of different nurses, with different levels of specialist expertise. At the least specialised end of the spectrum are health visitors and district nurses who have generic community nursing roles. Health visitors are mainly involved with well children and mainstream child 
development activities. While the focus of district nursing is the care of ill adults not children. Practice nurses, attached to general practitioner (GP)/family practitioner surgeries, also have generic roles connected to the provision of primary health care, for example, childhood immunisation programmes. In some localities, teams of community children's nurses (CCNs) have been established; these nurses support the home based care of children who have chronic illnesses, have been recently discharged from hospital or are at risk of hospital (re)admission. CCNs are therefore skilled in the care of children with more severe, complex and less common health problems. However, they may still not be familiar with some of the equipment and complex procedures involved in the day-to-day care of a technology-dependent child. Some specialist hospital departments have developed Clinical Nurse Specialist (CNS) posts; these nurses work across the hospital/ community interface to support both families providing care for children with particular medical conditions (which may include technology-dependence) and the generic community-based health professionals who may be involved in supporting them locally.

\section{Research methods}

Qualitative research methods were used to explore the experiences of parents caring for a technology-dependent child and of the health professionals supporting them in the community. The study investigated what support parents wanted, what they actually received and how congruent these were with professionals' perceptions. 'Support' was defined in the context of this study as interactions or behaviours that enabled parents to care for their child at home. The study explored the types and sources of support professionals provided and parents received. (Although the study also explored parents' experiences of lay social support systems, these are not covered in this paper.)

\subsection{Sample selection and recruitment}

The parents of 24 technology-dependent children were recruited from three specialist children's hospitals. The sample was purposively selected to include a range of technologies, lengths of time that children had been at home and patterns of community support services. Families were provided with information about the study by hospital staff who obtained parental consent to pass on their details to the researcher. The researcher then contacted families by telephone to discuss their participation in the study and arrange an interview at their home. Parents' written consent was obtained at the interview. Local ethical committee approval was obtained prior to the fieldwork.
Parents provided the names of all the professionals involved in the home care of their child. From this sampling frame, 38 professionals were purposively selected to cover a range of different professionals - nurses, doctors, social workers and teachers. In addition, three health authority purchasers were interviewed about their experiences of commissioning services for this group of children, as were three nurses responsible for planning the discharge from hospital of children with continuing complex health needs. The interviews with professionals did not focus on the study children but explored more generally their experiences of working with technology-dependent children and their families at home.

\subsection{Data collection}

Face-to-face, in-depth qualitative interviews lasting between 1 and $3 \mathrm{~h}$ were conducted with parents (23 mothers and 10 fathers) and professionals. Interview guides were used for the general direction of the interviews but participants were encouraged to direct the conversation into areas of importance for them. In relation to support, the interviews explored participants' experiences and views on the sources and type of support received or provided and their satisfaction with the quality and quantity of support.

\subsection{Data analysis}

All interviews apart from two were tape-recorded and fully transcribed. In these two interviews notes were taken during the course of the interview. Grounded Theory methods were used in the data analysis (Strauss and Corbin, 1998), with the Non-numerical Unstructured Data Indexing Searching Theory (NUD*IST) building computer program being used to code and explore the data (Qualitative Solutions and Research, 1997). Codes were identified in the data which were systematically compared and contrasted and then clustered together to create categories.

\subsection{Sample characteristics}

The children in the sample were dependent on a range of technologies, many on more than one (Table 1). They ranged in age from four months old to 17 years old and the majority had been at home for between 1 and 3 years. Only one family from an ethnic minority group of the three approached agreed to participate in the study. The composition of the professional sample is presented in Table 2. 
Table 1

The technological dependencies of the children in the sample $(n=24)$

\begin{tabular}{lc}
\hline Technological dependence & Number \\
\hline Tracheostomy & 10 \\
Oxygen therapy & 8 \\
Mechanical ventilation & 6 \\
Intravenous drugs & 4 \\
Parenteral nutrition & 2 \\
Peritoneal dialysis & 2 \\
Others (e.g. gastrostomy) & 13 \\
\hline
\end{tabular}

Table 2

The sample of professionals $(n=44)$

\begin{tabular}{ll}
\hline Professional & Number \\
\hline Clinical nurse specialists & 7 \\
Community children's nurses & 5 \\
Clinical nurse specialists & 5 \\
District nurses & 4 \\
Home carers & 4 \\
General practitioners & 4 \\
Community-based social workers & 4 \\
Community paediatricians & 3 \\
Hospital social workers & 3 \\
School head teachers/teachers & 2 \\
Health authority purchasers & 3
\end{tabular}

\section{Findings}

The intensiveness and complexity of the care needed by technology-dependent children and the uniquely high levels of expertise and knowledge which parents possessed about their child and her/his care transformed conventional parent-professional relationships and roles.

\subsection{Working with expert parents}

Parents' expertise was rooted in both the knowledge they had derived from the training programmes they had undergone before their child's discharge from hospital and in the experiential and intuitive knowledge derived from their subsequent experience of caring for their child. Working with these parents was acknowledged by professionals to be different, as it was often parents rather than professionals who were the experts in the child's care. This could transform the nature of the parent-professional relationship as well as roles of professionals themselves.

"Very often these parents become the knowledgeable experts in the care of their child and we respect that and, you know, we're perhaps seeing that child for an hour per week and the parents are with them $24 \mathrm{~h}$ a day and it sometimes becomes quite difficult-well not difficult for us but you know we have a supportive role rather than a caring role which is what we're trained to do. But for the other families that we visit, there's what we call routine work; you're going in as the expert because they've not met that condition before." Community Children's Nurse 01

Only a small minority of professionals reported feeling threatened by parent's expertise, although some parents felt that some generic community-based professionals had avoided them because they felt threatened by parents' superior knowledge. Honesty in relation to professional limitations, as described in the data extract below was seen an important factor in promoting a more trusting, egalitarian relationship between parents and professionals.

"We're not going in as the big 'I am', telling them what to do... we can't go in and say 'oh well you should be doing this, you should be doing that'. And I think we can tend to go in and the baby's laying on the floor on the mat, and we can sort of all sit down on the floor in front of the fire and say, 'oh gosh that's interesting, we've not seen one of those before, you know'. And mum or dad will say, 'Oh well, you do this and you do that'. And we learn from it and I think it helps them to know that there are things that they can teach us. And then I think they're not so intimidated by us and find that they can - 'Oh well, you know, she's quite happy to learn from us', and then they'll be quite happy to learn perhaps from our advice." District Nurse 01

Parents valued having their expertise acknowledged by professionals in this way; however, this was not always the case, leading to conflictual relationships.

\footnotetext{
"She wanted us to put this stuff in his milk to make him have more weight, and we did, and it were making him vomit like, ... I just stopped giving him that anyway and he started to pile the weight on better without it... when the nutritionist found we weren't giving him this, she really were telling me that I was going to give him this, but I knew I weren't because he were vomiting terribly. And she liked jetstreamed to this doctor to start telling me, and he said "oh no, you must carry on" and I thought oh I'm not letting him have it. I know it's not working out." Father of Nicholas Newton
}

Continuity in parent-professional relationships was identified by both parents and professionals as being important in developing a relationship characterised 
by mutual recognition of respective knowledge and expertise.

\subsection{The meaning of 'support'}

In describing the help they needed and valued, and that which they received, there was a high degree of congruence between the accounts of parents and professionals. Support had three dimensions-emotional support, instrumental or practical help, and information. In addition, nurses considered that part of their role was to ensure that parents performed clinical procedures safely.

\subsection{Providing emotional support}

Three aspects of emotional support were identified from the data: "being there"; listening/counselling; and promoting parents' self-confidence.

\subsection{1. "Being there"}

Parents found it reassuring to know that there was someone who was familiar with their child's circumstances, who was easy to contact and personally approachable if they needed help, advice or information-someone who "was there for them". Parents felt that this type of support promoted their confidence and helped them to cope with caring for their child. A range of professionals were identified by parents as providing this type of support, but CNSs in particular were singled out. The fact that CNSs and CCNs usually carried mobile phones was felt to make them more accessible than other professionals such as health visitors and social workers, where messages often had to be left at their offices.

"I know she's [CNS] always there, so that's a very good support and it helps to know that there is somebody there all the time and always on the end of a phone." Mother of David Davis

"It was always good to know that there was somebody there, just for the slightest problems, you know. They probably thought 'Oh it's nothing,' but to us it was something we thought was quite important." Mother of Edward Ellis

Having an easily accessible source of professional advice and help could also reduce the intrusion of professionals into the home as parents could seek help when they needed it.

"It's a nice feeling of security, that you're not at home and that's it, you know, all leads are cut and that's it; you're at home and 'Right you've got everything you need, ta, ta, that's it you can cope on your own'. It's nice to know that there is everybody out there willing to help when it's needed. So you're not, although you're as near normal as you possibly can with the limitations you've got, you're not tied and bound by all these, authorities and everything, and these various people; you know they're there in the background, but they're not hammering on your door, 'Oh I've come to see you'. It's just nice security that you know you've got them there." Mother of Victoria Wallace

However, not all parents could identify such a professional who they could contact if needed.

"I've actually got no back up at all. I need to know a phone number for someone who I can phone to get help...just someone I can phone who can come out... if somebody had just been on the end of the phone for us it would have been nice." Mother of Christopher Cooper

Professionals also recognised that parents valued knowing that there was someone to whom they could turn for help and support.

"Sometimes it's that they know that they can actually get hold of you at any sort of time, they find quite reassuring...it's just knowing that there's actually somebody out there. It helps them cope." Community Children's Nurse 03

\subsubsection{Listening and counselling}

A second element of emotional support which parents identified was being able to talk to and share with a professional who was familiar with the family, any worries or anxieties they might be experiencing.

"Just being able to talk to somebody who knows what her problems are, so you don't have to go through the rigmarole of explaining everything and going through all the blah, and all the rest of it." Mother of Victoria Wallace

Professionals also recognised that enabling parents to express their feelings and concerns was an important aspect of providing emotional support.

"I guess the main thing is that when I go round I'm usually there about an hour, and I'll just ask them how things are and listen to any concerns or worries, and talk about how $\mathrm{P}$ is doing... listening to any concerns that they might have." Health Visitor 04

Indeed, some nurses remarked that they would like additional training in counselling skills to enable them to perform this aspect of their role more effectively.

\subsubsection{Promoting parents' self-confidence}

The nurses in the study felt they had an important role to play in building and maintaining parents' confidence 
in caring for their child. Although parents had been taught how to care for their child prior to discharge from hospital they often felt anxious and less than confident at first without the back-up of the ward staff.

"[I'll say] 'Have a go; if you can't do it I'll take over...I'll phone you at so and so, and see how you've got on. And if you can't do it don't worry, I'll just come and help you.' And then it's just sort of given them that extra support... they've got to believe in themselves and it's just a case of building up their confidence to believe in themselves, that they can do it." Community Children's Nurse 04

Moreover, learning to judge whether to adjust the child's medication or when to call out a doctor, if the child seemed unwell, was not easy. Indeed, a wrong judgement could have serious-even fatal-consequences. Nurses therefore recognised they had an important role to play in developing parents' confidence by providing reassurance and reinforcing their decisions.

"They're asking your opinion whether they should seek medical help or something. But they knew before you, you know, they are more expert than you. They are just wanting your reassurance to say, 'Well that's right, that's what you should do'." Community Children's Nurse 02

\subsection{Providing practical support}

Parents valued the practical help they received from professionals as this could make a considerable difference to the work involved in caring for their child. Again, analysis of the study data identified three types of practical support; advocacy, "hands-on" care and organising services and equipment.

\subsubsection{Advocacy}

Both parents and professionals identified how professionals could act as an advocate on the family's behalf, for example, by writing to charities, supporting parents' applications for disability benefits and trying to obtain appropriate support services.

"In the case of the respite meeting that we had, she was there for that. You know she's my sort of backup if you will, she speaks on our behalf as much as anything." Mother of David Davis

Nurses also recognised this element of their role.

"We're always battling on the side of the patients and their families. And we've just been battling for 2 years to get them recombinant Factor 8 [for haemophilia] and we as nurses are playing a large part, as individuals... supporting the families, writing letters for the families, and I convene meetings for the families. I started the parents' support group where this all started, encouraged the parents to fight for Factor 8." Clinical Nurse Specialist 05

Professionals could also act as an intermediary with other workers on the family's behalf and thus take the pressure off parents who were considered to have enough to cope with in just looking after their child without having to organise professional services as well.

"Some of the families, there are times when they just want everybody to stop and they want some time to breathe and be their own. And I have done it informally a couple of times, with children. ...I'd actually just sit and count how many people [were involved]. And the parents just wanted for a couple of months to be on their own with their child. And I was, if you like, their advocate and just said to people, 'Just hold off, give them a couple of months and then contact [the family again].' And it worked very well, and they actually, the relationship between them, the professionals like the physio and the OT, actually became much better." Community Children's Nurse 03.

\subsection{2. "Hands-on" care}

Although parents were the main providers of care for their child, nurses nevertheless could provide some elements of "hands-on" care, usually in relation to procedures that were either only intermittently required or where it was anticipated that over time the parents would assume responsibility. Examples included taking blood samples, dressing wounds, administering injections, passing naso-gastric tubes and flushing intravenous lines. In addition, a small number of nurses provided "hands-on" support in order to give the parents a break from caring. The extract from the data below illustrates just how helpful this support could be for parents.

"She just does it all; she'll come out once in the middle of the week and she gives you a break and does the afternoon one... I mean it's only one but you think, 'Oh I can't wait for A (CNS) to get here,' because she just does the lot you know, does all the preparing and everything...I mean it doesn't sound much but you can get up and do the morning one and I can think to myself, 'Gosh I've got until 10 o'clock tonight without having to do one, because A is going to come and do it, you know', so it's nice." Mother of Ian Knight

However, the provision of "hands-on" care could be problematic for some parents. It may not simply be that there was no nursing support locally, but that they considered the "hands-on" support which was available to be inappropriate for their child. Generic community- 
based nurses could lack the expertise to perform the clinical procedures the child needed. Some district nurses were also concerned that they were being expected to support parents by performing procedures which, as generic adult nurses, were beyond their scope of practice.

"I asked the paediatric nurses if they'd ever done this as well on the ward. 'Oh no, we don't do that, the doctor does that' But they wanted to discharge this baby into my care, for me to do this and even observing the doctor doing it, he had great difficulty. That was just unacceptable." District Nurse 03

Overall, however, all the nurses in this study considered that providing "hands-on" care was only a minor element of their work in supporting parents with the home care of their technology-dependent child.

"I see our role as really helping the family to manage the child themselves at home. I don't see our role as to go in and do, actively do treatments. Our role is to hand over to the parents on a gradual basis and teach them to be able to manage situations and problems, supporting and advising them, more than actually going in and physically doing things." Clinical Nurse Specialist 02

\subsubsection{Organising services and equipment}

All the professionals in this study played some kind of role in organising services and equipment to help families care for their child at home, both in preparation for the child's discharge from hospital and subsequently, as the child's and family's needs changed. However, both parents and professionals reported problems in relation to this type of support, particularly where the provision of equipment and medications, and obtaining a break from caring, were concerned. Problems arose in both areas first, because it was not clear who was responsible for funding these services in the community and secondly because services appropriate for children who needed very specialised care were often simply not available in the community.

"I've had a real performance trying to get this family some respite care. There's been absolutely nothing, because there's no, sort of, nursing respite care really in this area at all. If it's been provided it's by voluntary groups, or by somebody like Crossroads, which is part funded by social services, and partly by the health authority and they don't really do any nursing kind of duties... So I mean this family had nothing in the way of support whatsoever, which was really awful for them. So in the end we have actually trained, well I trained somebody up in conjunction with the parents [to provide respite care]." Community Children's Nurse 04
A number of families criticised local community nursing services (including community children's nursing services) for their poor arrangements for obtaining equipment and consumable supplies. These parents consequently continued to rely on the specialist hospital from which their child had been discharged to provide supplies if none were available from local community nursing services; this was particularly problematic for families living far from the specialist regional hospital or who had no transport of their own. For many families, problems in obtaining adequate supplies was a source of considerable stress; some parents reported having had disputes with nurses and general practitioners over the quantity of consumables needed. The provision of equipment appeared to be particularly problematic for children with a tracheostomy.

"I order my things through the district nurses, in the way of suction catheters and trachie tubes. But I still get the feeling that they make you feel like, you know, you shouldn't be using this much stuff (laughs). I mean it's important, it's a matter of life and death to David... You'd also think they were spending their own money sometimes, it seems so stupid and petty...I've nearly run out of trachie tubes, basically because they forget to order them sometimes. ... It shouldn't happen. It's not fair, you know you're sat here then worrying, thinking 'well what am I going to do now, where do I go, what happens if they're not here?" Mother of David Davis.

In addition few parents reported that any local healthcare professional had assumed responsibility for co-ordinating the supply of equipment and services which they needed for their child. Consequently, many parents reported having had to adopt this co-ordination role themselves, in addition to the other aspects of their child's care.

\footnotetext{
"People think because you're a parent you're there to care for your child whatever happens, to fight for what they need, and their rights. But I felt a lot of the time I was the kingpin in what was happening, people were asking me....and I thought, you know, this is just not right is it? ...I felt I was the person correlating all the care and it was a mega-weight when you're under stress... It gets a very heavy load to carry... I think there should be somebody, I think that's the thing where it fell down - somebody to sort of correlate everything and communicate because it sometimes feels that people don't communicate, you know." Mother of Louise Parsons.
}

Even in those areas which had established community children's nursing teams, these were often still very new with some of the nurses still undertaking courses to prepare them to work in community settings. Conse- 
quently, some CCNs felt they still did not know enough about how community services were funded and organised to be able to support parents in this respect.

\subsection{Providing information}

The third dimension of support, again identified by both parents and professionals, was the provision of information. Again, there were three aspects to this.

\subsubsection{Advice and information-giving}

Professionals identified advice and information-giving to be a key part of their role; information was provided on a wide range of topics, including illness management, care-giving, services, benefits and equipment. Parents also valued the provision of information, not just because of its intrinsic practical usefulness but because it also contributed to an enhanced sense of autonomy and control. However, obtaining appropriate, timely information was an area where parents reported many problems. Many reported that they had to ask for information or had to seek it out themselves.

"When he had his gastrostomy, I kept asking for information on it, I said, 'there must be something in print somewhere that will help me, to learn all the do's and dont's'. And they always said, 'yeah we'll get you something'... but nothing, I asked and asked and asked... in the end all I could say before I left was, 'what's the worse thing I can do?' And they said feed him too fast. Well nobody had told me that. I mean if I hadn't asked they wouldn't have told me." Mother of Christopher Cooper

Information which was offered was often insufficient or conflicting, so that parents felt confused and uncertain. Inappropriate information, which did not take account of the child's needs, was also sometimes provided.

Parents assessed and made judgements about the level of expertise and knowledge that professionals possessed. They assessed that health visitors and district nurses (and generalist family doctors and local general hospitals as well) lacked specialist knowledge and consequently had few expectations of them being able to provide advice relating to their child's clinical care.

\subsubsection{Teaching}

Teaching parents to understand their child's condition and care was an important element of the role of specialist nurses, particularly CNSs and CCNs. Although parents had been taught the technical procedures involved in their child's care before s/he had been discharged from hospital, community-based nurses would show parents how to adapt what they had been taught to the home environment. The need for parents to perform new procedures, such as managing a naso-gastric tube, could also arise after the child had returned home.

"What we actually do is to look at the home side of it, because it is actually very different. And so whereas they may be doing TPN on the ward, where you have all the trolleys and all the rest of it, when they go home I'll go home first. So that when the parents first set it up we can actually look at...the pure logistics of it - 'Where do I put this? And what can I open this on? And how should I manage this?' Because it's very different in the home... we would teach them how to adapt to that." Clinical Nurse Specialist 02

Nurses also taught parents about the appropriate use of equipment; about the implications of the child's medical condition, such as cystic fibrosis or haemophilia; about diet; stimulating their child; and safety.

\subsubsection{Giving feedback}

Some professionals emphasised the importance of giving parents positive feedback, which fully acknowledge their knowledge and expertise and the complex responsibilities they were undertaking.

"I think just being there, saying good things-it sounds patronising, but just to say 'Well done!' and give them a pat on the back, recognise that they are doing a job-'Well done' - and somebody has come along and said well done...people don't praise parents enough, they don't say 'Well done, you have worked hard.' They usually tend to come down on the negative. As I said, you know, it's very difficult when you've got a child 24 hours a day, you've got to give them praise, and you've got to say well done." Community Children's Nurse 03

Parents similarly appreciated positive feedback, as Helen's father noted it made him feel that not only was he caring well for his daughter but that he was contributing directly to improvements in her condition.

"When a professional comes up to me and says 'Wow, your baby is ten times better than we expected,' then it's not only a complement but I feel that I'm doing the best for my daughter." Father of Helen Quinn

However, nurses saw themselves as being responsible for ensuring that children received appropriate clinical care and that procedures were carried out safely. Some nurses saw monitoring of parental care-giving as important and regularly assessed parental competency and compliance with procedures. A minority of nurses felt that they needed to retain some control over parent's care-giving and formally assess parent's competency on 
a regular basis to ensure adherence to the 'correct' procedure.

"I do audits as, maybe every year, on a number of families. So I can see that they are sticking to the programme protocol...we have to keep some control, in order to make sure that the standard of care is being kept and they are doing the right things." Clinical Nurse Specialist 05

Most nurses, however, took a more informal, covert approach to assessing parents' competency at caregiving.

"I mean with the TPN and things like that you'd have to actually arrange to go. But with the trachies when you're visiting, invariably they suck out and they do the procedures in front of you there and then. So quite often you do get to see that, and so you do get to monitor it. I wouldn't say we formally would do it. We would also be able to tell from the supplies they were using, and other ways, if we thought something was perhaps not quite right. And in that case we would arrange to visit. So, you know, obviously with the TPN if they got an infection or something like that, we would be looking at the technique and everything for it. But we wouldn't ring up and say, right every 6 months we're going to come and check what you are doing. Because I think that's very difficult for parents." Clinical Nurse Specialist 02

This surveillance role added a new dimension to the relationships between parents and professionals. It involved a degree of clinical supervision and scrutiny which was more characteristic of relationships between novice and expert professionals and reflected nurses concerns over their accountability for clinical caregiving by parents. While responsibility for clinical procedures had been clearly transferred to parents, nurses were unclear whether or not it had been accompanied by accountability. Monitoring parents care-giving involved treading a difficult line between being supportive and encouraging to parents and, at the same time, maintaining sufficient distance to be able to monitor and, if necessary, take action in the case of unsafe clinical practice.

"I think the more intense the relationship you have with these families, that the more difficult it can be, because you still want them to see you as a professional, but because you're going into their homes and sitting on their sofas and drinking their coffee-you know, they may start to see you as their friend. And I always think that's quite difficult to keep up that professionalism, because if you haven't got that professionalism then you can't offer them advice, and about things that they may or may not be doing correctly... There was this one child that I used to go to...it was apparent to me through the observations that I made, that she hadn't actually been getting her overnight feed. And that was very difficult, that was a very difficult thing for me to tackle. Because it was like I was the spy really... But at the end of the day we're all there for the child, and if people aren't doing what you ask them to do, you know, a feed is a prescription and if people aren't adhering to it then it's something that you have to tackle... But at the time it was very difficult for me." CNS 01

However, actual unsafe practice or poor standards of parental care were reported to be rare; when they did arise, nurses' first line of action was to work in close collaboration with other professionals, to improve the quality of parental care-giving.

\section{Conclusions}

Caring at home for a technology-dependent child involves parents carrying out complex clinical procedures which, in a hospital environment, would be undertaken by professionals. Parents therefore combine being mothers and fathers to their child (and to other children in the family) with the provision of skilled nursing care, on which their child's wellbeing and, indeed, survival depends. The latter involves not just acquiring technical competencies, in areas which are far from commonly taught, but also complex clinical decision making.

The nature of this care transforms relationships between parents and professionals, particularly nurses, whose professional roles overlap most closely with those of parents and who are likely to have a lead role in monitoring and supporting parents at home. In particular, nurses are likely to find themselves working with parents whose technical competence, at least in the areas of care required by their child, is as great as that of nurses. Indeed, community nurses who have a generic role in relation to the health of the general population, are very likely to find that the expertise of such parents far exceeds their own, particularly if much of their work involves adults, rather than children. Even community children's nurses may find they have less knowledge than parents. In the context of these reconfigured relationships, what are the implications for professional roles and activities? What kinds of help can professionals provide which will support parents in carrying these very onerous and highly skilled responsibilities?

This study has revealed a number of professional activities which were highly valued by parents. Moreover, there was an exceptionally high level of agreement between parents and nurses about these valued 
activities. This is not to imply, even in the small sample interviewed here, that parents always received this help nor that professionals always provided it. Although not the subject of this paper, parents reported instances in which the support they felt they needed had not been forthcoming, or where encounters with professionals or services had been unhelpful, stressful and even hostile. However, the high degree of congruence between parents' and professionals' understanding of the notion of 'support' and exactly what it entailed provides a strong basis for considering how professional skills and expertise can be enhanced.

First and foremost, it was of the utmost importance that professional nurses recognised and openly acknowledged parents' expertise — not just their technical skills, but their expertise in applying these to their child. It was the recognition of this individualised expertise which was so important and which underpinned positive and supportive parent-professional relationships. This meant that professionals had to be willing to learn new skills from parents and offer reassurance and confirmation to parents still unsure about their own clinical judgements. In contrast, 'experts' who failed to acknowledge their expertise or who questioned their judgement about the child's need for treatment caused parents anger and distress, not least because of the potentially serious consequences for the child's condition.

Both parents and nurses recognised the importance of an easily accessible source of information and advice to which parents could turn in case of uncertainty or anxiety. Community children's nursing services which were able to offer round-the-clock contact in case of emergency were particularly valued. This easy accessibility did not necessarily entail a major workload. Professionals recognised that often they just needed to offer advice, reassurance and confirmation that parents' were taking the correct course of action. In doing so, they were boosting parents' self-confidence in their own expertise and contributing to further transformations in the balance of professional-parent relationships. However, being prepared to spend time listening and providing counselling for parents was also important at times, given the stress experienced in providing this level of care.

A further area of activity recognised by both parents and professionals as crucially important was the provision of practical help. This rarely involved replacing parents by taking over practical aspects of the child's nursing care, at least on a routine basis. What parents valued-and professionals recognised was needed - was help with obtaining services and financial support, and with co-ordinating the many different services which parents and children required. Obtaining and co-ordinating such services was a source of considerable stress for a number of parents, who commonly had difficulties obtaining equipment and routine clinical supplies for their children and who also found themselves acting as a channel of communication between the many different professionals who visited the home. Even some nurses experienced difficulty themselves in obtaining - and maintaining - regular clinical supplies for the families they worked with.

Although there currently may be only around 6000 technology-dependent children living at home in across the UK as a whole (Glendinning et al., 2001), there are many more people, both adults and children, living in the community, who need intensive and complex nursing care. This study has illustrated the ways in which professional activities may need to be transformed to respond to this changing situation. In particular, the growing number of lay people-parents, spouses, children-who find themselves providing complex, technical and intensive nursing care suggests a growing professional emphasis on supportive, rather than instrumental activities, with advice, counselling and advocacy as increasingly valuable professional skills. This is not to imply that specialist technical competence and expertise is no longer important-far from it, because only from this basis can professionals provide reassurance and enhance the confidence and abilities of parents. However, given the changing patterns of hospital discharge and home care, providing information, advice and education, counselling, emotional support and service co-ordination are likely to become increasingly important—and valued-professional skills.

\section{Acknowledgements}

The study reported here was commissioned by the Department of Health as part of its 'Supporting Parenting' research initiative. However, the views expressed in this paper are those of the authors alone. The authors would like to thank the research participants for so willingly giving their time to share their experiences with the researcher.

\section{References}

Aday, L.A., Wegener, D.H., Anderson, R., Aitkin, M., 1989. Home care for ventilator assisted children. Health Affairs 8 (2), 137-147.

Andrews, M.M., Nielson, D.W., 1988. Technology dependent children in the home. Pediatric Nursing 14(2) 111-114, 151.

Baldwin, S., Carlisle, J., 1994. Social Support for Disabled Children and Their Families: a Review of the Literature. HMSO, London.

Beresford, B., 1994. Positively parents: caring for a severely disabled child. Social Policy Research Unit, University of York, York. 
Beresford, B., 1995. Expert Opinions: a National Survey of Parents Caring for a Severely Disabled Child. Policy Press, Bristol.

Chamba, R., Ahmad, W., Hirst, M., Lawton, D., Beresford, B., 1999. On the Edge: minority ethnic families caring for a severely disabled child. The Policy Press, Bristol.

Coyne, I., 1997. Chronic illness: the importance of support for families caring for a child with cystic fibrosis. Journal of Clinical Nursing 6, 121-129.

Department of Health, 1991. Welfare of Children and Young People in Hospital. HMSO, London.

Department of Health, 1996. Child Health in the Community: a Guide to Good Practice. HMSO, London.

Department of Health, 1998. Evaluation of the Pilot Project Programme for Children with Life-Threatening Illnesses. Department of Health, London.

Diehl, S., Moffitt, K., Wade, S.M., 1991. Focus group interviews with parents of children with medically complex needs: an intimate look at their perceptions and feelings. Children's Health Care 20 (3), 170-178.

Eiser, C., 1993. Growing up with a Chronic Disease: the Impact on Children and their Families. Jessica Kingsley, London.

Glendinning, C., 1983. Unshared Care: Parents and their Disabled Children. Routledge \& Kegan Paul, London.

Glendinning, C., 1985. A Single Door: Social Work with the Families of Disabled Children. Allen \& Unwin, London.

Glendinning, C., Kirk, S., Guiffrida, A., Lawton, D., 2001. The community-based care of technology-dependent children in the UK; definitions, numbers and costs. child: Health, Care and Development 27 (4), 321-334.

Gravelle, A.M., 1997. Caring for a child with a progressive illness during the complex chronic phase: parents' experience of facing adversity. Journal of Advanced Nursing 25, $738-745$.

Hall, S., 1996. An exploration of parental perception of the nature and level of support needed to care for their child with special needs. Journal of Advanced Nursing 24, 512521.

Hayes, V., Knox, J., 1984. The experience of stress in parents of children hospitalised with long-term disabilities. Journal of Advanced Nursing 9, 333-341.

Jennings, P., 1990. Caring for a child with a tracheostomy. Nursing Standard 4(30) 24-26 and 4(32) 38-40.

Kirk, S., 1998. Families experiences of caring at home for a technology-dependent child: a review of the literature. Child: Care, Health and Development 24 (2), 101-114.

Kirk, S., 1999. Caring for children with specialised health care needs in the community: the challenges for primary care. Health and Social Care in the Community 7 (5), 350-357.

Kirk, S., 2001. Negotiating lay and professional roles in the care of children with complex health care needs. Journal of Advanced Nursing 34 (5), 593-602.
McKeever, P., 1991. Mothering chronically ill technologydependent children: an analysis using critical theory. Ph.D. Thesis, York University, Toronto, Canada.

Middleton, L., 1998. Consumer satisfaction with services for disabled children. Journal of Interprofessional Care 12 (2), 223-231.

Pelletier, L., Godin, G., LePage, L., Dussault, G., 1993. Social support received by mothers of chronically ill children. Child: Care, Health and Development 20, 115-131.

Petr, C.G., Murdock, B., Chapin, R., 1995. Home care for children dependent on medical technology: the family perspective. Social Work in Health Care 21 (1), 5-22.

Qualitative Solutions and Research, Ltd., 1997. QSR NUD*IST (Version 4) [Windows]. Qualitative Solutions and Research, Melbourne.

Quint, R.D., Chesterman, E., Crain, L., Winkleby, M., Boyce, T., 1990. Home care for ventilator dependent children. American Journal of Diseases in Children 144, 1238-1241.

Scharer, K., Dixon, D., 1989. Managing chronic illness: parents with a ventilator dependent child. Journal of Pediatric Nursing 4, 236-247.

Sloper, P., Turner, S., 1992. Service needs of families of children with severe disability. Child: Care, Health and Development $18,250-282$.

Stacey, M., 1994. Lay knowledge: a personal view. In: Popay, J., Williams, G. (Eds.), Researching the People's Health. Routledge, London

Stallard, P., Lenton, S., 1992. How satisfied are parents of preschool children who have special needs with the services they have received? a consumer survey. Child: Care, Health and Development 18, 197-205.

Stewart, M., Ritchie, J., Mcgrath, P., Thompson, D., Bruce, B., 1994. Mothers of children with chronic conditions: supportive and stressful interactions with partners and professionals regarding caregiving burdens. Canadian Journal of Nursing Research 26 (4), 61-82.

Strauss, A., Corbin, J., 1998. Basics of Qualitative Research: Techniques and Procedures for Developing Grounded Theory. Sage, Thousand Oaks, CA.

Wheeler, T., Lewis, C.C., 1993. Home care for medically fragile children: urban versus rural settings. Issues in Comprehensive Paediatric Nursing 16, 13-30.

Whyte, D., 1992. A family nursing approach to the care of a child with chronic illness. Journal of Advanced Nursing 17, 317-327.

Young, L., Creighton, D., Sauve, R., 1988. The needs of families of infants discharged home with continuous oxygen therapy. Journal of Obstetric Gynaecological and Neonatal Nursing 17 (3), 187-193.

Youngblut, J., Brennan, P., Swegart, L., 1994. Families with medically fragile children: an exploratory study. Pediatric Nursing 20 (5), 463-468. 